\title{
ON THE FORMATION OF MEXICO STATE
}

\author{
D. E. SANTOS REYES \\ I'chi Research and Engineering, Santos Reyes Yucuna, Huajuapan de Leon, Oaxaca, Mexico.
}

\begin{abstract}
The process of change of very large systems, such as a country, is essentially described as a succession of chronological events. This viewpoint provides some critical issues regarding the development of the system of interest. However, it may not describe the dynamics of critical historical events occurring throughout the formation of the system. There is a need to pay attention not only to critical historical events, but also to the dynamics of the step changes. How did Mexico State evolve to be the way it is today? How regulated has it been through time? This is an attempt to escape from the traditional chronological description of historic events. Complexity science provides new and more fruitful conceptions, and more effective ways for studying self-organisation and self-regulated complex systems. This paper explores a major step change of the origin of modern Mexico State: pre-Aztec and Aztec dominion. The aim is to develop a fundamental understanding of the complexity of Mexico State system behaviour throughout its formation. This is with the aim to develop models that can be employed in engineering the future step changes of the system.

Keywords: change, complexity, novelty, systems.
\end{abstract}

\section{INTRODUCTION}

Complexity science studies the emergent behaviour of highly interconnected systems, such as healthcare, education, economic and social systems [1-3]. On the other hand, there has been a significant effort by historians to develop a great deal of understanding of historical events throughout the formation of very large social systems such as a country. However, very little attention has been given to the study of the dynamics of the complex process of formation of such systems through time. This papers explores the following issues: how very large systems, such as a country: Mexico, might have evolved through a very long period of time. This is, how did Mexico State evolved to be the way it is today? How regulated has it been through time? Section two revises relevant issues related to complexity and systems whilst section three presents the approach adopted here to study the situation of interest. Section four describes the initial insights gained at this exploration stage of the study and finally some concluding remarks are provided in section five.

\section{COMPLEXITY, SYSTEMS AND STATE FORMATION}

\subsection{Complexity and systems}

According to the online Collins English dictionary [4], complexity is 'the state or quality of being intricate or complex.' Similarly, complexity is defined by scholars as the number of distinguishable states of the elements of a given situation or system and the measure of complexity is called variety [5-7]. Complexity science, on the other hand, is an approach to study the emergent behaviour of complex systems, such as healthcare, education, economic, and social systems [8-10]. A system or a given situation is usually understood as a set of interrelated entities or parts. According to Beer [5], systems are distinguished by a set of interrelated parts, which are a systematically arranged assemblage, and the system serves a clear function or purpose. Furthermore, Beer emphasises that systems are very complex, highly probabilistic, 
and to some extent self-regulating. The systemic nature of very complex systems provides us with the very features required for the study of their behaviour and control.

\subsection{Social systems}

Biologists define evolution as a gradual change or development of living systems to a more complex state. Scholars have used this insight to study the behaviour of man-made systems, including social systems [11, 12]. According to some contemporary views, evolution may be characterised by phases of equilibrium interrupted by changes and destruction [13]. Catastrophic events, such as natural disasters, economic crisis, social unrest, etc. can be said to be systems' response to input changes at the verge of chaos [7]. These transient responses of systems affect dramatically on human life and on the natural environment. Such events may be regarded as the consequence of the obtrusive relationships between agents or parts that constitute a given situation or system. It seems that the connectivity of systems controls these novel catastrophic events. This provides great opportunity for scientific understanding of complex systems. The future time evolution of very complex social systems would be inherently very difficult to predict [14]. This does not prevent, however, the application of the scientific method for the study of novel or extreme events, as discussed by many scholars, such Boisot and McKelvey [15]. The notion of complex systems as pervasive in real life situations is relatively new, and its application to develop understanding of the intricate complexity of social systems is increasing. The behaviour of social systems is regulated by the richness of their connectivity and interactions.

\subsection{State formation}

History may be defined as the study of the past, i.e. the production of knowledge about past events. Marwick [16] emphasises that 'history is the body of knowledge about the past, as produced by historians, and the past is everything which actually happened, whether known, or written about by historians, or not.' In general, past events are studied and reported as a succession of chronological isolated events. State formation from an anthropological view point is to study all human culture and related issues [17]. The issue addressed here is how very large systems, such as a country: Mexico, might have evolved through a very long period of time. This is how did Mexico State evolve to be the way it is today? How regulated has it been through time?

\section{THE APPROACH}

There has been a significant effort by historians to develop a great deal of understanding of historical events throughout Mexico state formation. However, very little attention has been given to the study of the dynamics of the complex process of the formation of Mexico through time. Thus, a ready-made database does not exist for the study of the evolution of Mexico as a complex system. Figure 1 shows the system-of-focus. Mexico does not exist in isolation, i.e. it is part of the world system. Similarly, it consists of a collection of interrelated subsystems that serve a clear purpose: survival of the whole. A possible benefit of this representation is the ability to shift analysis from the system-of-focus to the lower level, i.e. subsystems level and to the world system. This enables one to analyse not only Mexico as a whole and its connectivity within the world system, but also the connectivity of various subsystem parts of the Mexico State. Furthermore, one can focus on the evolution of the complex 


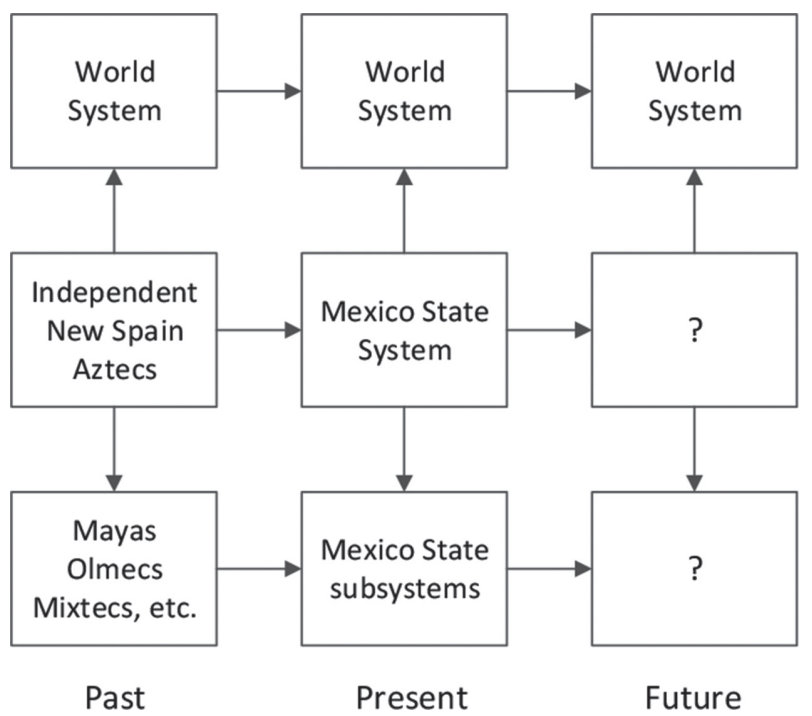

Figure 1: The system of focus: Mexico State System (adopted from [18]).

system through a very long period of time. In this exploratory study, the historian's approach is used in order to develop an understanding about how very large systems, such as Mexico evolved from a series of interactions over a very long period of time. This is, study the past of Mexico by gathering data/facts from archives, books and on-line published records from the first nations, such as Mayas, Olmecs, Zapotecs, Mixtecs, Chichimecs, etc. Finally, with the aid of complexity science principles one should be able to unfold the complexity of the formation of Mexico, from lower to higher levels of recursion and from the distant past to the present, including the near future.

\section{THE MEXICO STATE SYSTEM}

\subsection{The present situation}

Mexico's official name is the United Mexican States. It is formed by 31 federal states and its capital city for the past two centuries is called Federal District. It is where the federal executive, legislative, and judicial systems reside. Currently, the Federal District name is in the process of change from a federal district to Mexico City, along with a new Constitution. Mexico is a federal republic with a territory of almost two million square kilometres [19]. Its territory has changed significantly through time. Currently, limits with the United States in the North and with Guatemala and Belize in the Southeast, and with an estimated population of over 120 million inhabitants. Today Mexico is considered as an emergent economy [20]. Its economic stability has been sustained according to the rules of the world-system. Its gross domestic product (GDP) is very poor. In addition to this, the GDP does not consider social welfare and other issues that affect the economy. Mexico is a member of the United Nations, the Organisation of Economic Cooperation and Development (OECD), the World Trade Organisation (WTO) amongst other organisations. The Mexican economic performance has gone through a series of crisis and as a result of this its economic growth is very poor. The mexican 
socio-economic- and political situation is about surrogate worlds. It is easy enough to accept that everything is steadily improving in the world of the very few (the 20 most powerful Mexican families) whilst the world of millions is getting steadily worse. It is acknowledged by many that the gap between the poor and rich is bigger than ever before [21].

On the other hand, corruption, impunity and crime are endemic. Mexicans have witnessed systemic corruption, which began in the early 1980s. Mexican institutions have automatically transferred public resources to special interests by virtue of formal structures, processes, and paradigms or methods. As discussed elsewhere [22] ordinary crime, and organised crime, such as human and weapon smuggling, drug trafficking, and terrorism have steadily increased over the last decades. Similarly, the healthcare and education systems are mostly funded by public money. However, the education system is characterised by poor performance at all levels. Significant effort has been paid by the Mexican government, over the last decades, to implement a healthcare system that intends to provide a comprehensive health service to a great number of Mexicans [23]. But, this system emphasises on a reactive approach rather than on proactive means to address more affectively the wellbeing of the Mexicans.

\subsection{The origins}

According to historians, Mesoamerica was a region that covered southern Mexico, Guatemala, Belize, Honduras, and El Salvador. This region was the home of the modern Mexican ancestors, namely Olmecs, Mayas, Zapotecs, Mixtecs, Otomies, Toltecs, Aztecs, amongst others. In 1521, the Spanish conquered the Aztecs and spread their control throughout this region. The Spanish dominion, as viceroyalty of New Spain, extended for about three hundred years. Following the war of independence, (1810-1821), the New Spain became Mexico. Throughout the post-independence period, the newly constituted country went through a series of economic instability and political changes. For example, Mexico lost one-third of its territory to the USA in the Mexican-American war from 1846 to 1848 . The stability of the country was further weakened by foreign intervention, such as that in 1862 by France, Great Britain (GB) and Spain. Furthermore, the country was involved in a civil war, and a domestic dictatorship throughout the second half of the 19th century. Finally, the Mexican revolution (1910-1921) led to the formation of the modern Mexico. In line with this, the stages of Mexico State formation can be distinguished as four major step changes namely the Aztec dominion, the Spanish conquest, the independence, and the Mexican revolution. The below section explores the Aztec domain from the perspective of complex system theory.

\subsubsection{The Aztec dominion}

The formation of Mexico can be traced back to the Mesoamerican period. The beginning consisted primarily in isolated nations (Fig. 1a) namely Olmecs, Mayas, Mixtecs, Toltecs, Zapotecs, Aztecs, etc. Recently, historians have recognised that some of these advanced civilisations appeared before others and some disappeared before others. However, they all existed and interacted at the same time at some point in the Mesoamerican period. Furthermore, the descendants of these civilisations, such as the Mixtecs, Zapotecs and Mayas still exist today. Many still walk barefoot and speak a language of their own. At the early stages of the formation of these nations, there were little or no interactions at all. They did not pertain to a coherent whole, thus the dashed circle in Figure 1a. The complexity, or the variety, of this situation may be defined as the number of distinguishable nations: 5. Nothing more is known about it. 
As time passed, these nations developed a sophisticated network of interactions with each other. Initially, the interaction of these nations may be characterised by, according to historians, economic or trade relationships. Later, these interactions became obtrusive and patterned (Figure 1b). This connectivity was characterised not only by trade, but also by social and political relationships. This adds more information to the analysis, i.e. the lines denote the complexity of this set of nations. According to Beer [5], the internal relationships within systems should be capable of change. This is, each relationship should take more than one state. This enables the system to evolve. Considering two states, the complexity of the set of nations in Figure $1 \mathrm{~b}$ may be defined as $2^{n(n-1)}=2^{5(5-1)}=2^{20}$. This is the complexity of the cooperative organisation of the set of nations in Figure 2b. However, this system was not regulated by a centralised control system, i.e. it may be regarded as self-organised system. It was disturbed at a certain period of time by the Aztecs. This may be regarded as one of the first step changes towards the birth of a very large system: Mexico. The Aztecs, after a period of pilgrimage, settled in the central Anahuac Valley, today Mexico City. The Aztecs dominated the Mesoamerican people until 1521. The Aztecs created a centralised control over the original people. Thus the continuous line circle in Figure 1c. However, although these people were under the Aztec's regulation they did not serve a clear purpose to the whole Aztec system.

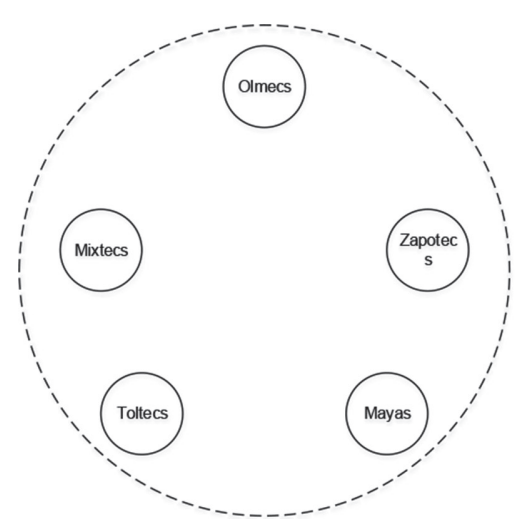

(a)

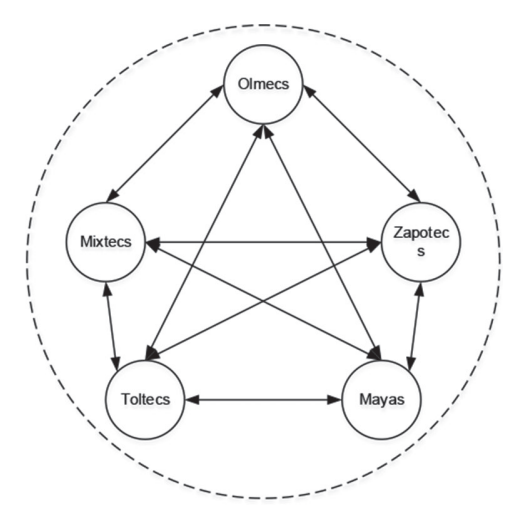

(b)

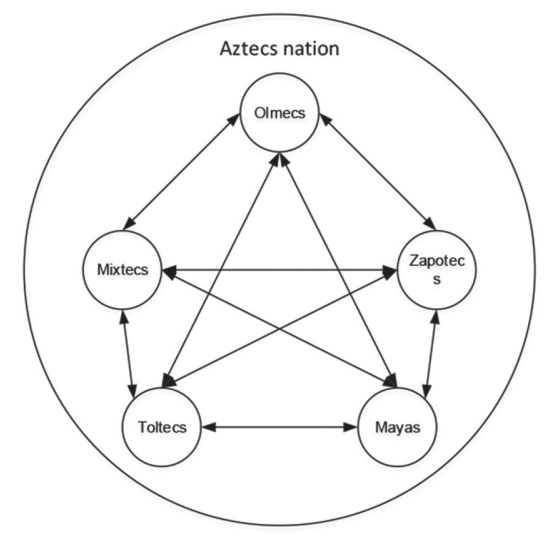

(c)

Figure 2: (a) early isolated nations, (b) dynamic system, (c) Aztecs nation. 
Owing to the resistance (inertia) of each group of these people, the change or transition to a new situation took a long period, in some cases the new situation, i.e. the Aztecs dominion, was never accepted by many original people. It may be said that the Aztecs dominion was a system of continuous oscillation. There was a need for some methods to bring the oscillations to an end. The whole Aztec system had little or no inherent damping, and the problem of obtaining a suitable response was the Spanish 'conquistadores'.

\section{CONCLUSIONS}

This paper explored the origins of the formation of Mexico State with the aid of complex system principles. It argued that the original peoples, namely Mayas, Olmecs, Zapotecs, Mixtecs, Toltecs, amongst others, developed a complex assemblage of relationships in the form of trade, social and political issues. However, this complex system did not develop a centralised form of control. It may be said that it was a self-organised system. The evolution of this system was disrupted by the Aztecs who established a centralised control over the original peoples. However, this can be considered as the first step change for the formation of Mexico. Future work will focus on detailed analysis of this initial exploration stage by means of qualitative and quantitative methods. Also, this will include qualitative and quantitative analysis of the other step changes: Spanish conquest, independence, and the so called Mexican revolution.

\section{REFERENCES}

[1] Jacobson, M. J. \& Wilensky, U., Complex systems in education: scientific and educational importance and implications for the learning sciences. Journal of the Learning Sciences, 15(1), pp. 11-34, 2006. https://doi.org/10.1207/s15327809j1s1501_4

[2] Diez Roux, A.V., Complex systems thinking and current impasses in health disparities research. American Journal of Public Health, 101(9), pp. 1627-1634, 2011. https://doi.org/10.2105/ajph.test.2011.300149

[3] Sawyer, R.K., Social emergence: Societies as complex systems, Cambridge University Press, NY, 2005.

[4] Collins English Dictionary, available at: https://www.collinsdictionary.com/dictionary/ english/complexity.

[5] Beer, S., Decision and Control, John Wiley \& Sons, 1994.

[6] Ashby, W.R., An introduction to cybernetics, Chapman \& Hall, London, 1957.

[7] Boisot, M. \& McKelvey, B., Integrating modernist and postmodernist perspectives on organizations: a complexity science bridge. Academy of Management Review, 35(3), pp. 415-433, 2010. https://doi.org/10.5465/amr.2010.51142028

[8] McKelvey, B., Salmador, M.P., \& Rodriguez-Anton, M., Towards an econophysics view of intellectual capital dynamics: from self-organized critically to the stochastic frontier. Knowledge Management Research \& Practice, 11, pp. 142-161, 2013. https://doi.org/10.1057/kmrp.2013.18

[9] Helbing, D., Managing complexity in socio-economic systems. European Review, 17(2), pp. 423-438, 2009. https://doi.org/10.1017/s1062798709000775 
[10] Davis, B. \& Simmt, E., Understanding learning systems: mathematics education and complexity science. Journal for Research in Mathematics Education, 34(2), pp. 137-167, 2003.

https://doi.org/10.2307/30034903

[11] Holland, J.H., Studying complex adaptive systems. Journal of Systems Science and Complexity, 19, pp. 1-8, 2006. https://doi.org/10.1007/s11424-006-0001-z

[12] Lansing, J.S., Complex adaptive systems. Annual Review of Anthropology, 32, pp. 183-204, 2003.

[13] Turcotte, D.L. \& Rundle, J.B., Self-organized complexity in the physical, biological, and social sciences. PNAS, 99(suppl. 1), pp. 2463-2465, 2002.

[14] Health Care as a Complex Adaptive System: Implications for Design Management. The Bridge, Spring, pp. 17-25, 2008.

[15] Boisot, M. \& McKelvey, B., Connectivity, extremes, and adaptation: a power-law perspective of organizational effectiveness. Journal of Management Inquiry, 20(2), pp. 119-133, 2011.

https://doi.org/10.1177/1056492610385564

[16] Marwick, A., The fundamentals of history, available at: https://www.history.ac.uk/ihr/ Focus/Whatishistory/marwick1.html

[17] Alonso, A.M., The politics of space, time and substance: State formation, nationalism, and enthinicity. Annual Review of Anthropology, 23, pp. 379-405, 1994.

https://doi.org/10.1146/annurev.anthro.23.1.379

[18] Altshuller, G.S., Creativity as an exact science: the theory of the solution of inventive problems, Amsterdam: Gordon and Breach, 1984.

[19] INEGI: Referencias geograficas y extension territorial de Mexico, available at: http:// www.inegi.org.mx/inegi/SPC/doc/internet/1-GeografiaDeMexico/MAN_REFGEOG_ EXTTERR_VS_ENERO_30_2088.pdf

[20] Aulakh, P.S., Kotabe, M. \& Teegen, H., Export strategies and performance of firms from emerging economies: evidence from Brazil, Chile, and Mexico, Academy of Management Journal, 43(3), pp. 342-361, 2000.

https://doi.org/10.2307/1556399

[21] Frausto, S., Los doce mexicanos mas pobres: el lado B de la lista de millonarios, Planeta, 2016.

[22] Santos-Reyes, D.E. \& Santos-Reyes, J.R. Patterns of temporal diffusion of crime in Mexico. International Journal of Safety and Security Engineering, 2(1), pp. 54-68, 2012.

https://doi.org/10.2495/safe-v2-n1-54-68

[23] Knaul, F.M. \& Frenk, J., Health insurance in Mexico: achieving universal coverage through structural reform Health Affairs, 24(6), pp. 1467-1476, 2005.

https://doi.org/10.1377/hlthaff.24.6.1467 